\title{
Infrastructure pricing and competition between modes in urban transport
}

\author{
Eric Pels, Erik T Verhoef \\ Department of Spatial Economics, Vrije Universiteit, De Boelelaan 1105, 1081 HV Amsterdam, \\ The Netherlands; e-mail: apels@feweb.vu.nl, everhoef@feweb.vu.nl \\ Received 21 October 2005; in revised form 20 May 2006
}

\begin{abstract}
Privatization of transit and roads is gaining increasing interest. This paper develops a model in which infrastructure pricing and optimal capacity are analyzed under both public and private regimes. It compares optimal outputs (number of passengers) and capacities of public and private operators of rail transport. A crucial aspect of the paper is competition between modes: for instance, how are optimal outputs and capacities of the private railway operator influenced by the strategic decisions on the road capacity and tolls for the private (car) alternative?
\end{abstract}

\section{Introduction}

Private operation of roads or transit companies may have certain benefits. Private operators may have better access to capital markets, so that the necessary funds for timely capacity expansions are more easily available. Furthermore, private operators may provide capacity in a more cost-effective manner and may operate it more efficiently, and may also be more innovative. There are, however, also potential economic hazards in private supply in transport. Private toll-road or transit operators typically maximize profits rather than social surplus. The control of a road (section) or the exclusive right to operate a rail transport network will imply a certain degree of market power (see Edelson, 1971; Mills, 1981). Profit-maximizing private road or paylane operators typically will set tolls higher than the optimal level (see De Palma and Lindsey, 2000; Verhoef et al, 1996). Profit-maximizing capacity, in contrast, will be below the optimum, although possibly optimal given the below-optimal demand. Similar arguments hold for private transport operators; prices can be expected to be above social marginal costs, and capacity below the first-best level.

The presence of private infrastructure operators may therefore raise interesting questions from the perspective of optimal transport policy and regulation, the consideration of which requires a good understanding of the operators' behaviour. The objective of this paper is to analyze the behaviour of private and public operators in an urban transport network, taking into account the fact that a competing mode is present. We will analyze how public and private companies set the optimal frequency, ${ }^{(1)}$ capacity, fares, and output levels in transit, and determine the welfare economic implications. We will also examine how a road charge influences travel demand, the rail fare, and ultimately welfare.

Although a private public transport company sets the prices above the marginal cost level, so that demand will be below the social optimum, an important question is

(1) In our analysis the public or private operator of a railway system sets a single frequency in multiple markets along a single line. We therefore do not cover networks in which the frequency of service may be different for the various links used in the trip. The single frequency on this line might be considered as a second-best instrument because the specific markets along the line are all served with the same frequency: market-specific frequencies are, by assumption, not possible. Given the fact that many rail or metro lines are operated in such a fashion this seems to be a reasonable assumption. 
whether the capacity and frequency offered by the private operator are also suboptimal, given the demand levels. This is an important aspect of the discussion on quality in urban transport.

The case of competing travel alternatives has already received attention in the literature (see, eg, Verhoef and Small, 2004). Recently, De Borger et al (2005) discussed tax competition in a network with two links, in which each link serves a local market (with no possibility for substitution) and a transit market (for which the two links are perfect substitutes). De Borger et al explicitly consider competition between two regulators, an aspect that is ignored in this paper. Arnott and Yan (2000) explicitly consider two competing modes, which are imperfect substitutes, in a synthetic overview of the literature. Other studies including competing modes include, amongst others, Glaister and Lewis (1978) and Parry and Small (2005). The current paper explicitly includes the aspect of multiple (complementary) links in a transport network and focuses on the interactions between congestion regulation in road transport on the one hand, and privatization and regulation in the rail sector on the other.

The paper is organized as follows. Section 2 introduces the general model, and section 3 introduces the specific network and specific model formulation to be used in the numerical analysis. Section 4 presents this numerical analysis. Section 5 presents a sensitivity analysis, and section 6 offers our conclusions.

\section{General form of the model}

\subsection{Utility and cost functions}

We consider the situation in which on each transport market [origin-destination (OD) pair] $j$, identical travellers are potentially active, and we assume that a representative traveller's utility is quasilinear:

$$
\mathrm{U}^{j}\left(q_{\mathrm{p}}^{j}, q_{\mathrm{r}}^{j}, q_{\mathrm{o}}^{j}\right)=\mathrm{u}^{j}\left(q_{\mathrm{p}}^{j}, q_{\mathrm{r}}^{j}\right)+q_{\mathrm{o}}^{j},
$$

where $q_{\mathrm{r}}^{j}$ is the 'consumption' of the rail alternative in market $j, q_{\mathrm{p}}^{j}$ is the 'consumption' of the private car alternative in market $j$, and $q_{\mathrm{o}}^{j}$ is the consumption of other goods with a unitary price. By assumption, a traveller is therefore active in at most one transport market $j$, an assumption that is made to keep the analysis transparent and that does not appear to be in any sense decisive for the results obtained. Furthermore, we assume that a traveller uses only one mode on a trip in market $j$. This reduces the number of travel alternatives, but without changing the intuition of the model. Following Arnott and Yan (2000), we assume that not all the traveller's income is spent on travel, so that we can write the utility-maximization problem as: ${ }^{(2)}$

$$
\underset{q_{\mathrm{p}}^{j}, q_{\mathrm{r}}^{j}}{\operatorname{maximize}} \mathrm{u}^{j}\left(q_{\mathrm{p}}^{j}, q_{\mathrm{r}}^{j}\right)+y^{j}-q_{\mathrm{p}}^{j} p_{\mathrm{p}}^{j}-q_{\mathrm{r}}^{j} p_{\mathrm{r}}^{j},
$$

where $y$ is income and $p_{i}^{j}$ is the price of alternative $i$ in market $j$. From equation (2), we can determine the inverse-demand function for both transport alternatives by deriving the first-order necessary conditions:

$$
p_{i}^{j}=\frac{\partial u^{j}(\cdot)}{\partial q_{i}^{j}},
$$

where $i$ denotes a mode. The full price, $p_{i}^{j}$, of mode $i$ in market $j$ is defined such that it equals the marginal private user $\operatorname{cost}, c_{i}^{j}$, plus a fee, $\tau_{i}^{j}$ (a road toll for the car

${ }^{(2)}$ Specifically, we assume that $q_{\mathrm{p}}$ and $q_{\mathrm{r}}$ are not constrained by income. Furthermore, we assume that all congestion effects are monetary, so that they are included in the utility-maximization problem through the budget constraint. 
alternative, or a fare for the public alternative):

$$
p_{i}^{j}=c_{i}^{j}+\tau_{i}^{j} .
$$

The marginal private user cost for the private car alternative in market $j$ is defined as the sum of link-specific costs. The marginal private user cost per link $k$, in turn, is a function of the total passenger flow over that link and the link capacity:

$$
c_{\mathrm{p}}^{k}=\mathrm{c}_{\mathrm{p}}^{k}\left(\sum_{j=1}^{J} \delta_{\mathrm{p}}^{j, k} n^{j} q_{\mathrm{p}}^{j}, w_{\mathrm{p}}^{k}\right),
$$

where $\delta_{\mathrm{p}}^{j, k}$ is a dummy that takes on the value 1 when link $k$ is used in market $j, n_{j}$ is the number of individuals that is potentially active in market $j$, and $w_{\mathrm{p}}^{k}$ is the road capacity of link $k$. The marginal private user cost for the private car alternative in market $j$ then is:

$$
c_{\mathrm{p}}^{j}=\sum_{k=1}^{K} \delta_{\mathrm{p}}^{j, k} c_{\mathrm{p}}^{k}=\sum_{k=1}^{K} \delta_{\mathrm{p}}^{j, k} \mathrm{c}_{\mathrm{p}}^{k}\left(\sum_{t=1}^{J} \delta_{\mathrm{p}}^{t, k} n^{t} q_{\mathrm{p}}^{t}, w_{\mathrm{p}}^{k}\right) .
$$

Similarly, the toll $\tau_{\mathrm{p}}^{j}$ in market $j$ is the sum of the relevant link tolls, if levied.

The marginal private user cost of the rail alternative is a function of the frequency of service, $f_{\mathrm{r}}$, the track capacity, $w_{\mathrm{r}}$, and, as a measure for convenience, the ratio of total passenger flow to total train (vehicle) capacity $v_{\mathrm{r}}$. For notational and analytical simplicity, we consider the case where a train runs back and forth along a line connecting several stations. The frequency of service and track capacity are constant across links (between stations). Because the frequency of service is the same across links, the (public or private) railway company sets only one frequency (that is, the frequency of service is the same in all markets using the same rail line). This in fact creates a second-best problem for the operator, but we chose to make this assumption for two reasons. One is that it is a common feature of railway lines that frequencies are equal between successive stops along the line. The other is that the determination of frequency and travel time for the long-distance market becomes very complicated when the frequencies of the two links are allowed to differ. The marginal private user cost becomes:

$$
c_{\mathrm{r}}^{j}=\mathrm{c}_{\mathrm{r}}^{j}\left(f_{\mathrm{r}}, w_{\mathrm{r}}, \sum_{k=1}^{K} \delta_{\mathrm{r}}^{j, k} \frac{\sum_{t=1}^{J} \delta_{\mathrm{r}}^{t, k} n^{t} q_{\mathrm{r}}^{t}}{f_{\mathrm{r}} v_{\mathrm{r}}}\right) .
$$

The regulator's or private operator's revenue (per mode) of offering the transportation alternative are $n^{j} q_{i}^{j} \tau_{i}^{j}$.

Next, we turn to the costs incurred by the infrastructure operators. The total cost for the rail operator falls into two categories: 'infrastructure cost' $C_{\mathrm{r}}^{\mathrm{s}}$ and 'traffic cost' $C_{\mathrm{r}}^{\mathrm{t}}$. Traffic costs depend on the capacity offered and the number of passengers carried. For simplicity we assume that traffic cost can be written as a function of frequency, $f_{\mathrm{r}}$, and train capacity, $v_{\mathrm{r}}$. In general, higher capacity trains can be assumed to lead to higher operational costs (energy use is higher, the costs of cleaning are higher, etc), but the operational costs are likely to increase less than proportionally with train capacity, $v_{\mathrm{r}}$. In particular, when the number of seats is increased, while the frequency, $f_{\mathrm{r}}$, remains constant, the driver (labour) cost can be spread out over a larger number of seats. When the cost per service remains constant with increasing frequency, we may then include a term $v_{\mathrm{r}}^{\xi} f_{\mathrm{r}}$ in the traffic-cost function. These costs exhibit constant returns to scale with respect to frequency and increasing returns to scale with respect 
to train capacity when $\xi<1$. Traffic cost may furthermore depend on the number of passengers carried. This makes up a second argument in the traffic-cost function (8). Thus, the traffic costs per link are:

$$
C_{\mathrm{r}}^{\mathrm{t}, k}=\mathrm{C}_{\mathrm{r}}^{\mathrm{t}, k}\left(v_{\mathrm{r}}^{\xi} f_{\mathrm{r}}, \sum_{j=1}^{J} \delta_{\mathrm{r}}^{j, k} n^{j} q_{\mathrm{r}}^{j}\right) .
$$

The total traffic costs are:

$$
C_{\mathrm{r}}^{\mathrm{t}}=\mathrm{C}_{\mathrm{r}}^{\mathrm{t}}\left(v_{\mathrm{r}}^{\xi} f_{\mathrm{r}}, \sum_{k=1}^{K} \sum_{j=1}^{J} \delta_{\mathrm{r}}^{j, k} n^{j} q_{\mathrm{r}}^{j}\right) .
$$

The infrastructure cost for the rail operator consists of the capacity costs (the cost of constructing capacities $w_{\mathrm{r}}^{k}$ for all links $k$ ):

$$
C_{\mathrm{r}}^{\mathrm{s}}=\sum_{k=1}^{K} \mathrm{C}_{\mathrm{r}}^{\mathrm{s}, k}\left(w_{\mathrm{r}}^{k}\right) .
$$

The road operator has a much simpler cost structure than the rail operator, and is assumed to face only infrastructure cost (traffic costs are fully borne by travellers). These can be written as:

$$
C_{\mathrm{p}}^{\mathrm{s}}=\sum_{k=1}^{K} \mathrm{C}_{\mathrm{p}}^{\mathrm{s}, k}\left(w_{\mathrm{p}}^{k}\right) .
$$

\subsection{User equilibrium}

Utility maximization under price-taking behaviour implies that, in the optimum, the marginal utility of using a mode equals the full price for all used mode-route combinations in market $j$, while unused options should have full prices exceeding marginal utility. When restricting attention to a single possible route for every market $j$ per mode, we can rewrite these 'Wardrop conditions' as:

$$
\left.\begin{array}{l}
q_{i}^{j}\left[\mathrm{c}_{i}^{j}(\cdot)+\tau_{i}^{j}-\frac{\partial \mathrm{u}^{j}(\cdot)}{\partial q_{i}}\right]=0, \quad q_{i}^{j} \geqslant 0, \\
\mathrm{c}_{i}^{j}(\cdot)+\tau_{i}^{j}-\frac{\partial \mathrm{u}^{j}(\cdot)}{\partial q_{i}^{j}} \geqslant 0, \quad i=\mathrm{p}, \mathrm{r}, \quad j=1, \ldots, J .
\end{array}\right\}
$$

\subsection{Social optimum}

With conditions (12), we have determined the traveller's equilibrium conditions. This equilibrium will depend on prices, capacity, and transit frequency. From a normative perspective it is instructive to derive which choice of instruments maximizes social surplus, our measure for social welfare. To derive these, we use conditions (12) as restrictions to the social surplus maximization problem. For interior solutions, with both modes in use in every market, the regulator's Lagrangian for first-best optimization is: ${ }^{(3)}$

$$
\begin{gathered}
\Lambda=\sum_{j=1}^{J} n^{j}\left[\mathrm{u}^{j}(\cdot)+y^{j}-\sum_{i=\mathrm{p}, \mathrm{r}} \frac{\partial \mathrm{u}^{j}(\cdot)}{\partial q_{i}^{j}} q_{i}^{j}\right]+\sum_{j=1}^{J} \tau_{\mathrm{r}}^{j} n^{j} q_{\mathrm{r}}^{j}+\sum_{j=1}^{J} \sum_{k=1}^{K} \delta_{\mathrm{p}}^{j, k} \tau_{\mathrm{p}}^{k} n^{j} q_{\mathrm{p}}^{j} \\
-\mathrm{C}_{\mathrm{p}}^{\mathrm{s}}(\cdot)-\mathrm{C}_{\mathrm{r}}^{\mathrm{s}}(\cdot)-\mathrm{C}_{\mathrm{r}}^{\mathrm{t}}(\cdot)+\sum_{i=\mathrm{p}, \mathrm{r}} \sum_{j=1}^{J} \lambda_{i}^{j}\left[\frac{\partial \mathrm{u}(\cdot)}{\partial q_{i}^{j}}-\mathrm{c}_{i}^{j}(\cdot)-\tau_{i}^{j}\right] .
\end{gathered}
$$

(3) In this case, the regulator both operates infrastructures and offers the railway service. The revenues of the railway services as well as the toll revenues for the private car alternative cancel out against the expenditures on tolls and fares in the objective function. 
Note that the rail fares are defined as being market specific, and the road tolls as link specific. The first large term in equation (13), with square brackets, represents consumer surplus as defined in equation (1). The next five terms give the operator's revenues minus costs, and therefore profits, for operating road and rail, respectively. The last term on the second line of equation (13) contains the restrictions representing consumer equilibrium conditions.

The first-order conditions are given in appendix A. Solving these yields the expected result that the optimal tolls and fares secure prices equal to the marginal social costs. Moreover, optimal frequency and capacities are such that the marginal social benefits of frequency or capacity are equal to their marginal cost.

\subsection{Profit maximization}

We now turn to the behaviour of a privatized rail or road operator. First consider the case in which the railway operation is privatized, while railway capacity remains under public control. Using equations (3) and (4), we can determine the private railway operator's revenues as

$$
R_{\mathrm{r}}=\sum_{j=1}^{J} n^{j} q_{\mathrm{r}}^{j}\left[\frac{\partial \mathrm{u}(\cdot)}{\partial q_{\mathrm{r}}^{j}}-\mathrm{c}_{\mathrm{r}}^{j}(\cdot)\right] .
$$

Profits are therefore:

$$
\pi_{\mathrm{r}}=R_{\mathrm{r}}-C_{\mathrm{r}}^{\mathrm{t}}-\mathrm{h}\left(\theta^{k}\right) .
$$

The third term on the right-hand side, $\mathrm{h}\left(\theta^{k}\right)$, is the total 'rent' paid to the regulator (that is, the operator of trackage) by the railway company for the use of the tracks; $\theta^{k}$ is the infrastructure charge paid per link.

The first-order necessary conditions for profit maximization can be written as:

$$
\begin{aligned}
& \frac{\partial \pi_{\mathrm{r}}}{\partial q_{\mathrm{r}}^{j}}=n^{j}\left\{\frac{\partial \mathrm{u}(\cdot)}{\partial q_{\mathrm{r}}^{j}}-\mathrm{c}_{\mathrm{r}}^{j}(\cdot)+\sum_{l=1}^{J} q_{\mathrm{r}}^{l}\left[\frac{\partial^{2} \mathrm{u}(\cdot)}{\partial q_{\mathrm{r}}^{l} \partial q_{\mathrm{r}}^{j}}-\frac{\partial \mathrm{c}_{\mathrm{r}}^{l}(\cdot)}{\partial q_{\mathrm{r}}^{j}}\right]\right\}-\frac{\partial C_{\mathrm{r}}^{\mathrm{t}}}{\partial q_{\mathrm{r}}^{j}}=0, \\
& \frac{\partial \pi_{\mathrm{r}}}{\partial f_{\mathrm{r}}}=-\sum_{l=1}^{J} n^{l} q_{\mathrm{r}}^{l} \frac{\partial \mathrm{c}_{\mathrm{r}}^{l}(\cdot)}{\partial f_{\mathrm{r}}}-\frac{\partial C_{\mathrm{r}}^{\mathrm{t}}}{\partial f_{\mathrm{r}}}=0, \\
& \frac{\partial \pi_{\mathrm{r}}}{\partial v_{\mathrm{r}}}=-\sum_{l=1}^{J} n^{l} q_{\mathrm{r}}^{l} \frac{\partial \mathrm{c}_{\mathrm{r}}^{l}(\cdot)}{\partial v_{\mathrm{r}}}-\frac{\partial C_{\mathrm{r}}^{\mathrm{t}}}{\partial v_{\mathrm{r}}}=0 .
\end{aligned}
$$

The first term in large brackets in equation (16) gives the travellers' marginal willingness to pay, and the second term is the user cost; both terms together define the fare paid by the passengers [equations (3) and (4)]. The other two terms give the conventional demand-related monopolistic markup, and a term that is equal to the marginal external congestion cost. The final term, outside the large brackets, is the marginal (traffic) cost faced by the rail operator. The fare is, therefore, set at marginal cost (congestion plus traffic) plus the monopolistic markup,

$$
q_{\mathrm{r}}^{l} \frac{\partial^{2} \mathrm{u}(\cdot)}{\partial q_{\mathrm{r}}^{l} \partial q_{\mathrm{r}}^{j}} .
$$

The internalization of congestion $q_{\mathrm{r}}^{l}\left[\partial \mathrm{c}_{\mathrm{r}}^{l}(\cdot) / \partial q_{\mathrm{r}}^{j}\right]$ is consistent with welfare maximization (see appendix A), but the monopolistic markup is not.

Comparison of equation (17) with equations (A4) and (A3), and equation (18) with equations (A8) and (A4), reveals that the profit maximizer applies optimal rules for setting frequency and train capacity (that is, equilibrium levels will differ from first-best levels only because quantities are different). This generalizes the more conventional 
result from studies on private roads, that a private road operator chooses optimal capacity given the level of road use emerging under its excessive charge (eg Small, 1992). The intuition behind this result of a profit maximizer supplying socially optimal capacity is that any reductions in average generalizer user cost, achieved through an investment in capacity or frequency, can be matched by an increase in the fare and hence average revenue without affecting demand. The profit maximizer thus faces the optimal incentive to minimize social cost for serving the inefficiently low number of travellers served.

The regulator may correct for market-power abuse by giving the private railway operator a subsidy per passenger carried [so that $\partial \Lambda / \partial q_{\mathrm{r}}^{j}$ from equation (13) and $\partial \pi_{\mathrm{r}} / \partial q_{\mathrm{r}}^{j}$ from equation (16) produce the same in equilibrium]. Comparing the firstorder conditions, one can determine that the regulator needs to implement a subsidy per market $j$ equal to

$$
\sum_{l=1}^{J}\left[\frac{\partial p_{\mathrm{r}}^{l}(\cdot)}{\partial q_{\mathrm{r}}^{j}}\right] q_{\mathrm{r}}^{l} .
$$

This subsidy is equal to the monopolistic markup over marginal costs, and gives the private railway company the proper incentive to set the output at the welfare-maximizing level. It is then straightforward to show that the optimal frequency of service for the public company is optimal.

In practice, it is far more likely that a private company pays a fixed price to the regulator or infrastructure operator for the use of the infrastructure, or a fixed price per train, rather than receiving a subsidy per passenger as required for the first-best solution. To study the effects and optimal value of such a price, we add an infrastructure charge $\theta_{\mathrm{r}}$ to the profit function:

$$
\pi_{\mathrm{r}}=R_{\mathrm{r}}-\theta_{\mathrm{r}} f-C_{\mathrm{r}}^{\mathrm{t}},
$$

where $\theta_{\mathrm{r}}$ is the infrastructure charge per train movement. When we add the first-order conditions for profit maximization (16)-(18) as additional restrictions to the regulator's optimization problem in equation (13), the constrained welfare maximization ensures that an equilibrium will be reached in which neither the passengers nor the operator have an incentive to change behaviour. The implications of such an infrastructure charge are analyzed numerically in section 4 . First, a specific network to be analyzed numerically will now be introduced in section 3 .

\section{Model specification for a network with three nodes}

Because insightful general solutions appeared hard or impossible to obtain for our model, and also because comparative static effects may differ from insights that can be obtained from marginal analysis, we proceed by introducing a simulation model that we will use in the remainder of this paper. Figure 1 illustrates a bimodal network with three nodes in which there are three different markets (AB, AC, and BC). Each market is served by both modes. A train runs from A to C, making a stop at B. Frequency, $f_{\mathrm{r}}$, and (train) capacity, $v_{\mathrm{r}}$, are the same on both rail links. Passengers travelling from A to $\mathrm{C}$ travel on both links of the (rail) network. Likewise, passengers travelling from $\mathrm{A}$ to $\mathrm{C}$ using the private car travel on both links in the (road) network. Congestion on the road between $\mathrm{AB}(\mathrm{BC})$ is thus caused by passengers in the $\mathrm{AB}(\mathrm{BC})$ and $\mathrm{AC}$ markets. User cost for travellers in the AC market, using the private car alternative, is the sum of the user costs on both links used in these markets [equations (4) and (5)]. User costs

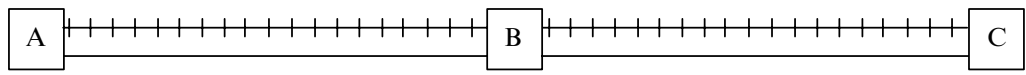

Figure 1. The transport network for the numerical model. 
for travellers using the rail alternative are defined separately for the three markets [equation (7)]. The specifications for the user-cost functions are given below.

Recall that we assume that preferences for travel in market (or OD pair) $j$ is independent of travel in other markets, by considering separate representative individuals for all markets. Assuming a quadratic structure for the subutility function $\mathrm{u}(\cdot)$ in equation (1), we can write the utility function for the three representative consumers as:

$$
\left.\begin{array}{c}
\mathrm{U}^{\mathrm{AB}}\left(q_{\mathrm{p}}^{\mathrm{AB}}, q_{\mathrm{r}}^{\mathrm{AB}}, q_{\mathrm{o}}^{\mathrm{AB}}\right)=\alpha_{\mathrm{p}}^{\mathrm{AB}} q_{\mathrm{p}}^{\mathrm{AB}}+\alpha_{\mathrm{r}}^{\mathrm{AB}} q_{\mathrm{r}}^{\mathrm{AB}}+\frac{1}{2} \beta_{\mathrm{p}}^{\mathrm{AB}}\left(q_{\mathrm{p}}^{\mathrm{AB}}\right)^{2}+\frac{1}{2} \beta_{\mathrm{r}}^{\mathrm{AB}}\left(q_{\mathrm{r}}^{\mathrm{AB}}\right)^{2} \\
+\gamma^{A B} q_{\mathrm{p}}^{\mathrm{AB}} q_{\mathrm{r}}^{\mathrm{AB}}+q_{\mathrm{o}}^{\mathrm{AB}}, \\
\mathrm{U}^{\mathrm{AC}}\left(q_{\mathrm{p}}^{\mathrm{AC}}, q_{\mathrm{r}}^{\mathrm{AC}}, q_{\mathrm{o}}^{\mathrm{AC}}\right)= \\
\alpha_{\mathrm{p}}^{\mathrm{AC}} q_{\mathrm{p}}^{\mathrm{AC}}+\alpha_{\mathrm{r}}^{\mathrm{AC}} q_{\mathrm{r}}^{\mathrm{AC}}+\frac{1}{2} \beta_{\mathrm{p}}^{\mathrm{AC}}\left(q_{\mathrm{p}}^{\mathrm{AC}}\right)^{2}+\frac{1}{2} \beta_{\mathrm{r}}^{\mathrm{AC}}\left(q_{\mathrm{r}}^{\mathrm{AC}}\right)^{2} \\
\quad+\gamma^{\mathrm{AC}} q_{\mathrm{p}}^{\mathrm{AC}} q_{\mathrm{r}}^{\mathrm{AC}}+q_{\mathrm{o}}^{\mathrm{AC}}, \\
\mathrm{U}^{\mathrm{BC}}\left(q_{\mathrm{p}}^{\mathrm{BC}}, q_{\mathrm{r}}^{\mathrm{BC}}, q_{\mathrm{o}}^{\mathrm{BC}}\right)=\alpha_{\mathrm{p}}^{\mathrm{BC}} q_{\mathrm{p}}^{\mathrm{BC}}+\alpha_{\mathrm{r}}^{\mathrm{BC}} q_{\mathrm{r}}^{\mathrm{BC}}+\frac{1}{2} \beta_{\mathrm{p}}^{\mathrm{BC}}\left(q_{\mathrm{p}}^{\mathrm{BC}}\right)^{2}+\frac{1}{2} \beta_{\mathrm{r}}^{\mathrm{BC}}\left(q_{\mathrm{r}}^{\mathrm{BC}}\right)^{2} \\
+\gamma^{\mathrm{BC}} q_{\mathrm{p}}^{\mathrm{BC}} q_{\mathrm{r}}^{\mathrm{BC}}+q_{\mathrm{o}}^{\mathrm{BC}},
\end{array}\right\}
$$

where $\alpha_{i}^{j} \geqslant 0, \beta_{i}^{j} \leqslant 0, \gamma^{j} \leqslant 0$.

Utility if maximized with respect to the budget constraints $y^{j}=p_{\mathrm{r}}^{j} q_{\mathrm{r}}^{j}+p_{\mathrm{p}}^{j} q_{\mathrm{p}}^{j}+q_{\mathrm{o}}^{j}$; $\forall j$. The price for good $q_{\mathrm{o}}^{j}$ is fixed at $1, \forall j$. The inverse-demand functions for the different travel alternatives can be determined from the first-order necessary conditions for utility maximization (after substitution of the budget constraint in the objective function):

$$
\frac{\partial \mathrm{U}^{j}(\cdot)}{\partial q_{i}^{j}}-p_{i}^{j}=0 \Leftrightarrow p_{i}^{j}=\alpha_{i}^{j}+\beta_{i}^{j} q_{i}^{j}+\gamma^{j} q_{-i}^{j}, \quad i=\mathrm{p}, \mathrm{r} ; j=\mathrm{AB}, \mathrm{AC}, \mathrm{BC} .
$$

To simplify notation while maintaining symmetry, we assume that the number of relevant potential consumers in each market $j$ is equal to $1: n^{\mathrm{AB}}=n^{\mathrm{BC}}=n^{\mathrm{AC}}=1$. Again, the full price $p_{i}^{j}$ is defined as the generalized user cost plus a toll (fare): $p_{i}^{j}=c_{i}^{j}(\cdot)+\tau_{i}^{j}$. For the private car alternative, the average user costs are assumed to be linear in the volume-capacity ratio, with intercepts $\chi_{0}^{j}$ and intercept $\chi_{1}^{j}$ :

$$
\begin{aligned}
& c_{\mathrm{p}}^{\mathrm{AB}}=\chi_{0}^{\mathrm{p}, \mathrm{AB}}+\chi_{1}^{\mathrm{p}, \mathrm{AB}} \frac{q_{\mathrm{p}}^{\mathrm{AB}}+q_{\mathrm{p}}^{\mathrm{AC}}}{w_{\mathrm{p}}^{\mathrm{AB}}}, \\
& c_{\mathrm{p}}^{\mathrm{BC}}=\chi_{0}^{\mathrm{p}, \mathrm{BC}}+\chi_{1}^{\mathrm{p}, \mathrm{AB}} \frac{q_{\mathrm{p}}^{\mathrm{BC}}+q_{\mathrm{p}}^{\mathrm{AC}}}{w_{\mathrm{p}}^{\mathrm{BC}}}, \\
& c_{\mathrm{p}}^{\mathrm{AC}}=c_{\mathrm{p}}^{\mathrm{AB}}+c_{\mathrm{p}}^{\mathrm{BC}} .
\end{aligned}
$$

For the rail alternative, the average user cost consists of three terms (apart from a constant), namely a congestion component, a frequency component, and a convenience component:

$$
\left.\begin{array}{l}
c_{\mathrm{r}}^{\mathrm{AB}}=\chi_{0}^{\mathrm{r}, \mathrm{AB}}+\chi_{1}^{\mathrm{r}, \mathrm{AB}} \frac{f_{\mathrm{r}}}{w_{\mathrm{r}}}+\chi_{2}^{\mathrm{r}, \mathrm{AB}} \frac{\phi_{\mathrm{r}}^{\mathrm{AB}}}{f_{\mathrm{r}}}+\chi_{3}^{\mathrm{r}, \mathrm{AB}} \frac{q_{\mathrm{r}}^{\mathrm{AB}}+q_{\mathrm{r}}^{\mathrm{AC}}}{f_{\mathrm{r}} v_{\mathrm{r}}}, \\
c_{\mathrm{r}}^{\mathrm{BC}}=\chi_{0}^{\mathrm{r}, \mathrm{BC}}+\chi_{1}^{\mathrm{r}, \mathrm{BC}} \frac{f_{\mathrm{r}}}{w_{\mathrm{r}}}+\chi_{2}^{\mathrm{r}, \mathrm{BC}} \frac{\phi_{\mathrm{r}}^{\mathrm{BC}}}{f_{\mathrm{r}}}+\chi_{3}^{\mathrm{r}, \mathrm{BC}} \frac{q_{\mathrm{r}}^{\mathrm{BC}}+q_{\mathrm{r}}^{\mathrm{AC}}}{f_{\mathrm{r}} v_{\mathrm{r}}}, \\
c_{\mathrm{r}}^{\mathrm{AC}}=\chi_{0}^{\mathrm{r}, \mathrm{AC}}+\chi_{1}^{\mathrm{r}, \mathrm{AC}} \frac{f_{\mathrm{r}}}{w_{\mathrm{r}}}+\chi_{2}^{\mathrm{r}, \mathrm{AC}} \frac{\phi_{\mathrm{r}}^{\mathrm{AC}}}{f_{\mathrm{r}}}+\chi_{3}^{\mathrm{r}, \mathrm{AC}} \frac{q_{\mathrm{r}}^{\mathrm{AB}}+q_{\mathrm{r}}^{\mathrm{BC}}+2 q_{\mathrm{r}}^{\mathrm{AC}}}{f_{\mathrm{r}} v_{\mathrm{r}}},
\end{array}\right\}
$$

where $\phi_{\mathrm{r}}^{j}$ is the traveller's valuation of the average headway $\left(1 / f_{\mathrm{r}}\right)$ between services. Note that, when the impact of congestion, convenience, and frequency on the generalized costs 
is negligible, one would typically expect that $\chi_{0}^{\mathrm{r}, \mathrm{AB}}+\chi_{0}^{\mathrm{r}, \mathrm{BC}}=\chi_{0}^{\mathrm{r}, \mathrm{AC}}$; the generalized cost of travelling in the long-distance market is the sum of the generalized costs in the short-distance markets. When we apply the same line of reasoning to the convenience component, it follows that $\chi_{3}^{\mathrm{r}, \mathrm{AB}}=\chi_{3}^{\mathrm{r}, \mathrm{BC}}=\chi_{3}^{\mathrm{r}, \mathrm{AC}}$. The unweighted addition $q_{\mathrm{r}}^{\mathrm{AB}}$ and $q_{\mathrm{r}}^{\mathrm{BC}}$ to twice $q_{\mathrm{r}}^{\mathrm{AC}}$ in the final term for $c_{\mathrm{r}}^{\mathrm{AC}}$ reflects our assumption that the two rail links are equally long.

The congestion component in (22) (related to $\chi_{1}$ ) captures, for instance, the fact that in the simple network speed might have to be reduced when the frequency of service is increased because the distance between trains must not fall below a certain threshold. ${ }^{(4)}$ The frequency component in (22) (related to $\chi_{2}$ ) reflects waiting time or scheduling benefits from an enlarged frequency. And the comfort component in (22) (related to $\chi_{3}$ ) reflects increased personal space by decreased passenger numbers per unit of capacity (space).

The total traffic costs for the railway operator, $C_{\mathrm{r}}^{\mathrm{t}}+\theta_{\mathrm{r}} f_{\mathrm{r}}$ are:

$$
C_{\mathrm{r}}^{\mathrm{t}}=C_{\mathrm{r}}^{\mathrm{t}, \mathrm{AB}}+C_{\mathrm{r}}^{\mathrm{t}, \mathrm{BC}}=\kappa_{f} v_{\mathrm{r}}^{\xi} f_{\mathrm{r}}+\kappa_{q}^{\mathrm{AB}}\left(q_{\mathrm{r}}^{\mathrm{AB}}+q_{\mathrm{r}}^{\mathrm{AC}}\right)+\kappa_{q}^{\mathrm{BC}}\left(q_{\mathrm{r}}^{\mathrm{BC}}+q_{\mathrm{r}}^{\mathrm{AC}}\right)+\theta_{\mathrm{r}} f_{\mathrm{r}},
$$

where $\theta_{\mathrm{r}}$ is the infrastructure charge per train, $\kappa_{f}$ is the cost per unit of capacity offered (excluding the infrastructure payment), and $\kappa_{q}^{j}$ is the cost per passenger in market $j$. We assume that the infrastructure charge is paid for a service from $\mathrm{A}$ to $\mathrm{C}$. We therefore do not distinguish between charges for the $\mathrm{AB}$ and $\mathrm{BC}$ legs. The infrastructure cost depends on the cost of constructing and maintaining capacity $w_{i}$. Assuming a linear form, infrastructure costs are:

$$
C_{\mathrm{r}}^{\mathrm{s}}=\mu_{\mathrm{r}}^{\mathrm{AB}} w_{\mathrm{r}}^{\mathrm{AB}}+\mu_{\mathrm{r}}^{\mathrm{BC}} w_{\mathrm{r}}^{\mathrm{BC}}, \quad C_{\mathrm{p}}^{\mathrm{s}}=\mu_{\mathrm{p}}^{\mathrm{AB}} w_{\mathrm{p}}^{\mathrm{AB}}+\mu_{\mathrm{p}}^{\mathrm{BC}} w_{\mathrm{p}}^{\mathrm{BC}},
$$

where $\mu_{m}^{j}$ is the cost per unit of capacity of mode $m$ in market $j$.

The above specifications for the utility function and cost functions are used in the following section to numerically determine the welfare effects of congestion pricing, infrastructure pricing, and investments in infrastructure in the competitive case. For the three-node network, we have a system of twenty-eight equations (first-order conditions) in twenty-eight unknowns: $q_{\mathrm{r}}^{\mathrm{AB}}, q_{\mathrm{r}}^{\mathrm{BC}}, q_{\mathrm{r}}^{\mathrm{AC}}, q_{\mathrm{p}}^{\mathrm{AB}}, q_{\mathrm{p}}^{\mathrm{BC}}, q_{\mathrm{p}}^{\mathrm{AC}}, \tau_{\mathrm{r}}^{\mathrm{AB}}, \tau_{\mathrm{r}}^{\mathrm{BC}}, \tau_{\mathrm{r}}^{\mathrm{AC}}, \tau_{\mathrm{p}}^{\mathrm{AB}}, \tau_{\mathrm{p}}^{\mathrm{BC}}$, $\tau_{\mathrm{p}}^{\mathrm{AC}}, f_{\mathrm{r}}, w_{\mathrm{r}}, v_{\mathrm{r}}, w_{\mathrm{p}}^{\mathrm{AB}}, w_{\mathrm{p}}^{\mathrm{BC}}$, and eleven Lagrange multipliers. Note that the equality of the number of equations and constraints as such, of course, is not a sufficient condition to obtain a unique equilibrium. We refrain from a formal analysis of existence and uniqueness of equilibrium.

\section{Numerical analysis}

This section will present some numerical results that further illustrate the comparative static properties of our model. Table 1 shows the parameterization for a symmetric case. It is not the purpose of this paper to accurately describe a real-life network; the numerical analysis is performed to show the working of the model and illustrate the comparative static properties. The parameters are therefore not intended to correspond to real-life values. Nevertheless, the parameter values are chosen such that the equilibrium price elasticity of demand has a value that does not deviate too much from empirical estimates. Moreover, the parameter values are chosen such that the congestion costs are a reasonable percentage of the operating costs. ${ }^{(5)}$

(4) An investment in capacity may thus also mean an investment in safety or operational procedures rather than actual knowledge.

(5) Also, the parameter values are such that we always find $\tau_{\mathrm{r}}^{\mathrm{AB}}+\tau_{\mathrm{r}}^{\mathrm{BC}} \geqslant \tau_{\mathrm{r}}^{\mathrm{AC}}$; if this condition did not hold true, rail passengers in the $\mathrm{AC}$ market would be better of buying tickets for the $\mathrm{AB}$ and $\mathrm{BC}$ markets rather than a ticket for the AC market. 
Table 1. Parameter values for the symmetric numerical model.

Demand characteristics Cost parameters Generalized cost parameters

\begin{tabular}{|c|c|c|c|c|c|}
\hline$\alpha^{\mathrm{AB}}$ & 25 & $\kappa_{q}^{\mathrm{AB}}$ & 4 & $\chi_{0}^{\mathrm{p}, \mathrm{AB}}=4, \chi_{0}^{\mathrm{p}, \mathrm{AB}}=4$ & \\
\hline$\alpha^{\mathrm{BC}}$ & 25 & $\kappa_{q}^{\mathrm{BC}}$ & 4 & $\chi_{1}^{\mathrm{p}}=2.75$ & \\
\hline$\alpha^{\mathrm{AC}}$ & 50 & $\kappa_{\mathrm{r}}$ & 1 & $\chi_{m}^{\mathrm{r}, j}=1 ; m=1,2,3 ; j=\mathrm{AB}, \mathrm{BC}, \mathrm{AC}$ & \\
\hline$\beta^{\mathrm{AB}}$ & -0.5 & $\mu_{\mathrm{r}}^{\mathrm{AB}}$ & 2 & $\chi_{0}^{\mathrm{r}, \mathrm{AB}}=4, \chi_{0}^{\mathrm{r}, \mathrm{AB}}=4, \chi_{0}^{\mathrm{r}, \mathrm{AB}}=8$ & \\
\hline$\beta^{\mathrm{BC}}$ & -0.5 & $\mu_{\mathrm{r}}^{\mathrm{BC}}$ & 2 & $\phi_{\mathrm{r}}^{\mathrm{AB}}$ & 5 \\
\hline$\beta^{\mathrm{AC}}$ & -0.4 & $\mu_{\mathrm{p}}^{\mathrm{AB}}$ & 2 & $\phi_{\mathrm{r}}^{\mathrm{BC}}$ & 5 \\
\hline$\gamma$ & -0.25 & $\mu_{\mathrm{p}}^{\mathrm{BC}}$ & 2 & $\phi_{\mathrm{r}}^{\mathrm{AC}}$ & 5 \\
\hline
\end{tabular}

We consider a symmetric case, in which both transport alternatives, and both short-distance markets, have identical demand characteristics, so that we may exclude subscripts denoting transport alternatives for the demand parameters. This is of course not a realistic assumption for most cities, but it helps in determining and understanding the effect of cost (structure) differences between nodes, independent of demand differences. Note that the assumption of equal demand parameters for both shortdistance markets $\mathrm{AB}$ and $\mathrm{BC}$ will result in the absence of any slack capacity in transit operation in equilibrium.

The equilibrium outputs and welfare for the base regime, in which the road tolls $\tau_{\mathrm{p}}^{j}$ are fixed at 0 for all markets $j$, are shown in table 2 . Because the user of the infrastructure (the public railway company) and the public operator of the infrastructure are the same, the infrastructure charge is now fixed at 0 . All fares, frequencies, and capacities are set so as to maximize social surplus.

The equilibrium price elasticity of demand for the rail services is similar to the elasticity reported for the medium-distance rail-market segment in London and the South East (Department of Transport, 2003). Generally speaking, the elasticities

Table 2. Equilibrium solution for the base regime: zero road tolls and public railway services.

Outputs and Welfare components charges
Other variables of interest

\begin{tabular}{lllrlr}
\hline$q_{\mathrm{r}}^{\mathrm{AB}}$ & 19.68 & Consumer surplus & 2807.44 & Rail profits & -196.89 \\
$q_{\mathrm{r}}^{\mathrm{BC}}$ & 19.68 & Rail fare revenues & 398.44 & Congestion costs, road & 1168.91 \\
$q_{\mathrm{r}}^{\mathrm{AC}}$ & 48.35 & Toll revenues & 0.00 & Congestion costs, rail & 35.51 \\
$q_{\mathrm{p}}^{\mathrm{AB}}$ & 27.01 & Infrastructure revenues & 0.00 & Convenience, rail & 16.45 \\
$q_{\mathrm{p}}^{\mathrm{BC}}$ & 27.01 & Rail operating costs & 595.33 & Frequency benefits & 61.03 \\
$q_{\mathrm{p}}^{\mathrm{AC}}$ & 61.92 & Rail infrastructure costs & 35.51 & Optimal frequency $f_{\mathrm{r}}$ & 7.18 \\
& & Road infrastructure costs & 380.42 & Optimal number of seats $v_{\mathrm{r}}$ & 50.47 \\
$\tau_{\mathrm{r}}^{\mathrm{AB}}$ & 3.11 & Total welfare & 2194.63 & Optimal rail capacity $w_{\mathrm{r}}$ & 17.75 \\
$\tau_{\mathrm{r}}^{\mathrm{BC}}$ & 3.11 & & & Optimal road capacity & 95.10 \\
& & & & $w_{\mathrm{p}}^{\mathrm{AB}}=\left(w_{\mathrm{p}}^{\mathrm{BC}}\right)$ & \\
$\tau_{\mathrm{r}}^{\mathrm{AC}}$ & 5.7 & & & Price elasticity, rail, AB & -0.57 \\
$\tau_{\mathrm{p}}^{\mathrm{AB}}$ & 0 & & & Price elasticity, rail, AC & -0.48 \\
$\tau_{\mathrm{p}}^{\mathrm{BC}}$ & 0 & & & Price elasticity, road, AB & -0.32 \\
& & & & & -0.32
\end{tabular}


reported in table 2 are in line with the elasticities reported in the survey of Oum and Waters (2000). ${ }^{(6)}$ Their survey shows that intracity rail and transit system market demand is, on average, a bit more elastic than automobile market demand. This is reflected in table 2.

The absence of congestion charging for cars leads to relatively low rail fares, via two different channels. First, demand for car transport is relatively high, which reduces demand for rail transport through the cross-price effect. Second, the rail fare is optimized in a second-best fashion, and therefore adjusted downward to compensate (partly) for the lack of congestion charge in road transport. Note that the rail infrastructure costs are equal to the rail congestion costs. This is no coincidence, and the mathematical derivation of this result is given in appendix $\mathrm{B}$, which derives this equality analytically for the linear specification also used here. ${ }^{(7)}$

The equilibrium in table 2 is not socially optimal, because road congestion is not internalized. Table 3 contains the surplus-maximizing solution. In this case, the regulator sets a welfare optimal road charge for the users of the private car alternative. The infrastructure charge is, again, fixed at 0 . Naturally, private car use decreases due to the implementation of the congestion toll. But the demand for rail transport also decreases due to the implementation of road pricing. This seems counterintuitive, but is caused by the fact that fares are optimized in both equilibria. In table 2 the absence of congestion pricing in road transport motivated the charging of relatively low transport fares. This motive disappears in table 3, with the result that fares rise and demand falls (slightly), while rail losses are reduced significantly.

The optimal outputs for both traffic alternatives are now set so that the social marginal costs are equal to the social marginal benefits. Optimal profits are higher compared with table 2, while the congestion tolls leads to a $14-18 \%$ decrease in demand. As a result, the congestion costs decrease by $19 \%$, and the optimal road capacity decreases by $8.5 \%$. The optimal number of rail passengers decreases a little. The consumer surplus decrease by almost $18 \%$, while the final increase in welfare is limited $(1.6 \%)$. Note that, in equilibrium, (road) toll revenues and road capacity costs are the same (see appendix B).

Next, table 4 contains the outcome for the following case: a private rail alternative and no road congestion tolls. Rail profits increase, and welfare decreases by almost $10 \%$ compared with the base equilibrium of table 2 , because the private rail operator exploits market power (that is, the private optimal railway outputs are below the welfare optimum).

The second-best infrastructure charge is negative, indicating that the regulator uses the infrastructure charge as a tool to diminish the effect of the exploitation of market power by the railway company. The infrastructure charge also seems to be rather small in absolute value; note that the private railway company is charged at $\theta=-0.24$ per train run. This amounts to a subsidy of roughly 0.06 per passenger, ${ }^{(8)}$ which is a

(6) Oum and Waters (2000) report the following demand elasticities (all in absolute values). The market demand elasticity for the automobile segment is in the range of $0.12-0.49$ (peak), $0.06-0.88$ (off-peak), or $0.00-0.52$ (all day). The elasticities for the (intracity) rail segment are 0.15 (peak), 1.00 (off-peak), and $0.12-1.80$ (all day). For the transit system, the values are $0.00-0.29$ (peak), $0.32-1.00$ (off-peak), and $0.01-0.96$ (all day).

(7) This is easily seen by changing the specification infrastructure costs. For instance, a quadratic specification $\left(C_{\mathrm{r}}^{\mathrm{s}}=\mu w_{\mathrm{r}}^{2}\right)$ leads to the finding that the congestion costs are $t$ wice the infrastructure costs.

(8) This amount is calculated as $\theta f_{\mathrm{r}}^{j} / \sum_{j} q_{j}:-0.24 \times 5.88 /(7.11+7.11+11.21)$. Note that in this simple calculation the difference between short haul $(\mathrm{AB}, \mathrm{BC})$ and long haul $(\mathrm{AC})$ markets is ignored. The $\theta$ for the $\mathrm{AB}$ and $\mathrm{BC}$ markets would typically be somewhat below 0.06 , while the $\theta$ would be expected to be somewhat higher, in absolute value, than 0.06 . 
Table 3. Welfare optimum; percentage change relative to the base regime.

\begin{tabular}{|c|c|c|c|c|c|c|c|c|}
\hline $\begin{array}{l}\text { Outputs and } \\
\text { charges }\end{array}$ & Value & $\begin{array}{l}\text { Percentage } \\
\text { change }\end{array}$ & Welfare components & Value & $\begin{array}{l}\text { Percentage } \\
\text { change }\end{array}$ & Other variables of interest & Value & $\begin{array}{l}\text { Percentage } \\
\text { change }\end{array}$ \\
\hline$q_{\mathrm{r}}^{\mathrm{AB}}$ & 19.65 & -0.15 & Consumer surplus & 2290.55 & -18.41 & Rail profits & -25.49 & -87.05 \\
\hline$q_{\mathrm{r}}^{\mathrm{BC}}$ & 19.65 & -0.15 & Rail fare revenues & 568.69 & 42.73 & Congestion costs, road & 941.45 & -19.46 \\
\hline$q_{\mathrm{r}}^{\mathrm{AC}}$ & 48.25 & -0.21 & Toll revenues & 347.96 & - & Congestion costs, rail & 35.46 & -0.14 \\
\hline$q_{\mathrm{p}}^{\mathrm{AB}}$ & 22.79 & -15.62 & Infrastructure revenues & 0.00 & - & Convenience, rail & 16.43 & -0.12 \\
\hline$q_{\mathrm{p}}^{\mathrm{BC}}$ & 22.79 & -15.62 & Rail operating costs & 594.18 & -0.19 & Frequency benefits & 60.95 & -0.13 \\
\hline$q_{\mathrm{p}}^{\mathrm{AC}}$ & 51.39 & -17.01 & $\begin{array}{l}\text { Rail infrastructure costs } \\
\text { Road infrastructure costs }\end{array}$ & $\begin{array}{r}35.46 \\
347.96\end{array}$ & $\begin{array}{l}-0.14 \\
-8.53\end{array}$ & $\begin{array}{l}\text { Optimal frequency } f_{\mathrm{r}} \\
\text { Optimal number of seats } v_{\mathrm{r}}\end{array}$ & $\begin{array}{r}7.18 \\
50.37\end{array}$ & $\begin{array}{r}0.00 \\
-0.20\end{array}$ \\
\hline$\tau_{\mathrm{r}}^{\mathrm{AB}}$ & 4.19 & 34.73 & Total welfare & 2229.6 & 1.59 & Optimal rail capacity $w_{\mathrm{r}}$ & 17.73 & -0.11 \\
\hline$\tau_{\mathrm{r}}^{\mathrm{BC}}$ & 4.19 & 34.73 & & & & Optimal road capacity $w_{\mathrm{p}}^{\mathrm{AB}}\left(=w_{\mathrm{p}}^{\mathrm{BC}}\right)$ & 86.99 & -8.53 \\
\hline$\tau_{\mathrm{r}}^{\mathrm{AC}}$ & 8.37 & 46.84 & & & & Price elasticity, rail, $\mathrm{AB}$ & -0.64 & - \\
\hline$\tau_{\mathrm{p}}^{\mathrm{AB}}$ & 2.35 & - & & & & Price elasticity, rail, AC & -0.57 & - \\
\hline$\tau_{\mathrm{p}}^{\mathrm{BC}}$ & 2.35 & - & & & & $\begin{array}{l}\text { Price elasticity, road, AB } \\
\text { Price elasticity, road, AC }\end{array}$ & $\begin{array}{l}-0.50 \\
-0.52\end{array}$ & $\begin{array}{l}- \\
-\end{array}$ \\
\hline
\end{tabular}


Table 4. Private rail operations and no road congestion charges; percentage change relative to the base regime.

\begin{tabular}{|c|c|c|c|c|c|c|c|c|}
\hline $\begin{array}{l}\text { Outputs and } \\
\text { charges }\end{array}$ & Value & $\begin{array}{l}\text { Percentage } \\
\text { change }\end{array}$ & Welfare components & Value & $\begin{array}{l}\text { Percentage } \\
\text { change }\end{array}$ & Other variables of interest & Value & $\begin{array}{l}\text { Percentage } \\
\text { change }\end{array}$ \\
\hline$q_{\mathrm{r}}^{\mathrm{AB}}$ & 6.83 & -65.28 & Consumer surplus & 2396.93 & -14.62 & Rail profits & 110.28 & -156.01 \\
\hline$q_{\mathrm{r}}^{\mathrm{BC}}$ & 6.83 & -65.29 & Rail fare revenues & 292.87 & -26.50 & Congestion costs, road & 1550.70 & 32.66 \\
\hline$q_{\mathrm{r}}^{\mathrm{AC}}$ & 13.49 & -72.10 & Toll revenues & 0.00 & - & Congestion costs, rail & 13.27 & -62.63 \\
\hline$q_{\mathrm{p}}^{\mathrm{AB}}$ & 33.28 & 23.21 & Infrastructure revenues & -1.54 & - & Convenience, rail & 7.19 & -56.29 \\
\hline$q_{\mathrm{p}}^{\mathrm{BC}}$ & 33.28 & 23.21 & Rail operating costs & 184.13 & -69.07 & Frequency benefits & 22.49 & -63.15 \\
\hline$q_{\mathrm{p}}^{\mathrm{AC}}$ & 83.32 & 34.56 & $\begin{array}{l}\text { Rail infrastructure costs } \\
\text { Road infrastructure costs }\end{array}$ & $\begin{array}{r}24.72 \\
484.15\end{array}$ & $\begin{array}{r}-30.39 \\
27.27\end{array}$ & $\begin{array}{l}\text { Optimal frequency } f_{\mathrm{r}} \\
\text { Optimal number of seats } v_{\mathrm{r}}\end{array}$ & $\begin{array}{r}6.04 \\
12.71\end{array}$ & $\begin{array}{l}-15.88 \\
-74.82\end{array}$ \\
\hline$\tau_{\mathrm{r}}^{\mathrm{AB}}$ & 7.68 & 146.95 & Total welfare & 1996.80 & -9.01 & Optimal rail capacity $w_{\mathrm{r}}$ & 12.36 & -30.37 \\
\hline$\tau_{\mathrm{r}}^{\mathrm{BC}}$ & 7.68 & 146.95 & & & & Optimal road capacity $w_{\mathrm{p}}^{\mathrm{AB}}\left(=w_{\mathrm{p}}^{\mathrm{BC}}\right)$ & 121.04 & 27.28 \\
\hline$\tau_{\mathrm{r}}^{\mathrm{AC}}$ & 13.93 & 144.39 & & & & Price elasticity, rail, $\mathrm{AB}$ & -2.59 & - \\
\hline$\tau_{\mathrm{p}}^{\mathrm{AB}}$ & 0.00 & - & & & & Price elasticity, rail, AC & -2.71 & - \\
\hline$\tau_{\mathrm{p}}^{\mathrm{BC}}$ & 0.00 & - & & & & Price elasticity, road, AB & -0.27 & - \\
\hline$\theta_{\mathrm{r}}$ & -0.26 & & & & & Price elasticity, road, AC & -0.25 & - \\
\hline
\end{tabular}


relatively small amount compared with the rail fares paid by each passenger. In fact, if we were to calculate the operator's optimal charge per passenger, rather than per train, the average subsidy per passenger would be much higher. ${ }^{(9)}$ To understand the intuition behind this, first note that the regulator uses the infrastructure charge (per train) to correct for the exploitation of market power (monopoly pricing). The charge affects the railway company costs via its frequency; so the regulator in fact influences the frequency of service in its attempt to reduce the markup over the railway company's marginal cost per passenger. Such a change in the frequency of service will have no impact on the marginal cost per passenger [equation (23)], but will, however, lead to a change in the generalized cost of travel [equation (22)]. The infrastructure charge thus has only an indirect effect on the rail fare (via the generalized costs) and gives no direct incentive to lower the fare. Furthermore, note that the first-order condition for welfare maximization with respect to frequency can be written as:(10)

$$
\frac{\partial \Lambda}{\partial f_{\mathrm{r}}}=-\frac{\partial \mathrm{C}_{\mathrm{r}}^{\mathrm{t}}(\cdot)}{\partial f_{\mathrm{r}}}-\sum_{j} \lambda_{\mathrm{r}}^{j} \frac{\partial \mathrm{c}_{\mathrm{r}}^{j}(\cdot)}{\partial f_{\mathrm{r}}}=0 .
$$

In the optimum (where $\lambda_{\mathrm{r}}^{j}=q_{\mathrm{r}}^{j}, \forall j$ ) this condition is the same as the profit-maximizing first-order condition with respect to the frequency:

$$
\frac{\partial \pi_{\mathrm{r}}}{\partial f_{\mathrm{r}}}=-\sum_{l} q_{\mathrm{r}}^{l} \frac{\partial \mathrm{c}_{\mathrm{r}}^{l}}{\partial f_{\mathrm{r}}}-\frac{\partial C_{\mathrm{r}}^{\mathrm{t}}}{\partial f_{\mathrm{r}}}=0 ;
$$

see also the discussion below equations (16) - (20). Thus, given the nonoptimal choice of $q_{\mathrm{r}}^{j}$, $\forall j$, the private railway company sets the welfare-maximizing frequency, and there is no reason to directly affect the frequency (the indirect reason being the indirect effect on nonoptimal aggregate demand). ${ }^{(1)}$ Because the effect of frequency upon demand is relatively small, the second-best optimal infrastructure charge will therefore give the railway company little incentive, apart from the indirect effect described above, to change the frequency. Note that the rail infrastructure costs are no longer equal to the frequency benefits in table 4: the regulator in table 2 sets a welfare-maximizing infrastructure capacity, while the private railway company sets a profit-maximizing frequency of service and train capacity.

Table 5 contains the outcomes for the case of the private rail alternative and welfare-maximizing congestion tolls. Because of the congestion toll, the generalized costs of road transport increase. As a result, the private railway operator can also increase the fares. Profits therefore increase. For the rest, we get the expected results. Output for the car alternative decreases, while welfare increases compared with table 4.

Finally, table 6 summarizes the relative importance of (a) the availability of a road toll to curb road congestion and (b) private or public control of rail, for social surplus. The relative efficiency indicator $(\omega)$ shown is defined as the ratio of gains in social surplus, with the numerator giving the surplus gain in the regime compared with the base regime (no toll, public rail), and the denominator giving the gain under first-best regulation, compared with the base regime. Negative relative efficiency therefore indicates a lower surplus than in the base regime. The results show that avoiding profit maximization in rail may be more important to social surplus than optimizing road congestion.

(9) The optimal infrastructure charges per passenger are: $\theta^{\mathrm{AB}}=\theta^{\mathrm{BC}}=-10.91 ; \theta^{\mathrm{AC}}=-22.02$. With these infrastructure charges the equilibrium outputs, fares, and welfare levels in table 2 are replicated.

(10) This is the condition for welfare maximization, without a private railway operator. Calculation of the first-order condition for welfare maximization and a private operator is more difficult.

(11) Note that this is a general result that does not depend on the linearity of the inverse-demand or cost functions. 
Table 5. Private rail operations and welfare maximizing road congestion charges; percentage change relative to the base regime.

\begin{tabular}{|c|c|c|c|c|c|c|c|c|}
\hline $\begin{array}{l}\text { Outputs and } \\
\text { charges }\end{array}$ & Value & $\begin{array}{l}\text { Percentage } \\
\text { change }\end{array}$ & Welfare components & Value & $\begin{array}{l}\text { Percentage } \\
\text { change }\end{array}$ & Other variables of interest & Value & $\begin{array}{l}\text { Percentage } \\
\text { change }\end{array}$ \\
\hline$q_{\mathrm{r}}^{\mathrm{AB}}$ & 8.83 & -55.11 & Consumer surplus & 1668.26 & -40.58 & Rail profits & 227.32 & -215.46 \\
\hline$q_{\mathrm{r}}^{\mathrm{BC}}$ & 8.83 & -55.13 & Rail fare revenues & 484.85 & 21.69 & Congestion costs, road & 1123.26 & -3.91 \\
\hline$q_{\mathrm{r}}^{\mathrm{AC}}$ & 20.10 & -58.43 & Toll revenues & 634.56 & - & Congestion costs, rail & 17.75 & -50.01 \\
\hline$q_{\mathrm{p}}^{\mathrm{AB}}$ & 25.73 & -4.74 & Infrastructure revenues & -1.54 & - & Convenience, rail & 9.01 & -45.23 \\
\hline$q_{\mathrm{p}}^{\mathrm{BC}}$ & 25.73 & -4.74 & Rail operating costs & 259.07 & -56.48 & Frequency benefits & 30.01 & -50.83 \\
\hline$q_{\mathrm{p}}^{\mathrm{AC}}$ & 62.79 & 1.41 & $\begin{array}{l}\text { Rail infrastructure costs } \\
\text { Road infrastructure costs }\end{array}$ & $\begin{array}{r}26.77 \\
415.16\end{array}$ & $\begin{array}{r}-24.61 \\
9.13\end{array}$ & $\begin{array}{l}\text { Optimal frequency } f_{\mathrm{r}} \\
\text { Optimal number of seats } v_{\mathrm{r}}\end{array}$ & $\begin{array}{r}6.29 \\
19.28\end{array}$ & $\begin{array}{l}-12.40 \\
-61.80\end{array}$ \\
\hline$\tau_{\mathrm{r}}^{\mathrm{AB}}$ & 8.65 & 178.14 & Total welfare & 2086.67 & -4.92 & Optimal rail capacity $w_{\mathrm{r}}$ & 13.38 & -24.62 \\
\hline$\tau_{\mathrm{r}}^{\mathrm{BC}}$ & 8.65 & 178.14 & & & & Optimal road capacity $w_{\mathrm{p}}^{\mathrm{AB}}\left(=w_{\mathrm{p}}^{\mathrm{BC}}\right)$ & 103.79 & 9.14 \\
\hline$\tau_{\mathrm{r}}^{\mathrm{AC}}$ & 16.52 & 189.82 & & & & Price elasticity, rail, $\mathrm{AB}$ & -2.13 & - \\
\hline$\tau_{\mathrm{p}}^{\mathrm{AB}}$ & 3.59 & - & & & & Price elasticity, rail, AC & -2.01 & - \\
\hline$\tau_{\mathrm{p}}^{\mathrm{BC}}$ & 3.59 & - & & & & Price elasticity, road, AB & -0.51 & - \\
\hline$\theta_{\mathrm{r}}$ & -0.24 & & & & & Price elasticity, road, AC & -0.49 & - \\
\hline
\end{tabular}


Table 6. The relative efficiency $(\omega)$ of various regulatory regimes (absolute welfare levels given in parentheses).

Public rail operations Private rail operations

\begin{tabular}{llll}
\hline No toll & $0(2194.63)$ & $-5.66(1996.8)$ \\
Toll & $1(2229.6)$ & $-3.08(2086.67)$
\end{tabular}

The size of the indicators are, of course, to a large extent determined by the relative initial shares of the two means, with rail being nearly as important as road (see table 2). But when rail is indeed important in urban transport, our results suggest that profit maximization in rail may have a strong negative effect upon social welfare, possibly exceeding the deadweight loss from uninternalized congestion. The net benefits from avoiding profit maximization depend partly on the question of whether road pricing is in place. Because the road toll can partly compensate for the distortion from private rail operation, one might expect these benefits to be smaller in the absence of road tolling, and this is indeed the case in our numerical model. We also find that the relative gain from introducing a road toll is bigger with private rail operations. The reason is that private rail operations boost road transport demand, and thus traffic congestion. The (second-best) optimal pricing of congestion therefore becomes more beneficial to overall social welfare.

\section{Sensitivity analysis: demand elasticity}

The results in the previous section are of course dependent on the parameterization of the model. Sensitivity analysis helps to assess the robustness of the results. Space constraints prevent us from performing an extensive sensitivity analysis. In this section we therefore analyze the relationship between some of the effects described above and the elasticity of demand, which we expect to be among the most important determinants of the relative efficiency of the regimes. The demand elasticity is not a parameter itself, so we investigate its impact by making simultaneous changes to the parameters $\alpha$ and $\beta$, and show the impacts as a function of the implied endogenous elasticity for the rail market $\mathrm{AB}$ in the equilibrium for the base regime. ${ }^{(12)}$ Because $\alpha$ and $\beta$ are assumed to be the same for rail and road markets, all elasticities will change simultaneously in this sensitivity analysis.

In the previous section we described how in the base regime (regime I), the regulator tries to correct the absence of a road toll by charging relatively low rail fares. As a result, the rail alternative is relatively cheap, so that road users have an incentive to switch to rail. When a road toll is implemented (regime II), the secondbest rail fare increases. Figure 2 shows the ratio between the rail fares in regimes I and II, in the AB market, as a function of the elasticity of demand, where the range of elasticities considered covers values found in the literature [see footnote (5)]. The rail fare in regime II is always higher than in regime I (all ratios are below 1), so that

(12) The exact approach is as follows. Scenario I, with public rail operation and no road toll, is chosen as the base case. First, we then determine the reservation price $\alpha$ as a function of $\beta$ so as to obtain different elasticities of demand for the same quantities $q$ when changing $\beta$ in the base case. This was realized technically be treating all output levels $q_{i}^{j}$ parametrically in the first-order condition for the base case, and solving for $\alpha$ as a function of $\beta$ for the resulting equation. Using these $\alpha \mathrm{s}$ and $\beta \mathrm{s}$ results in the same output, capacities, frequency levels, and congestion levels as in the base case, at different values of the demand elasticity. Thus, when analyzing how the effect of, for instance, a congestion toll varies with the demand elasticity, we always start with the same equilibrium. Next, these new values of $\alpha$ and $\beta$ were used in the optimization problems for the other scenarios. 


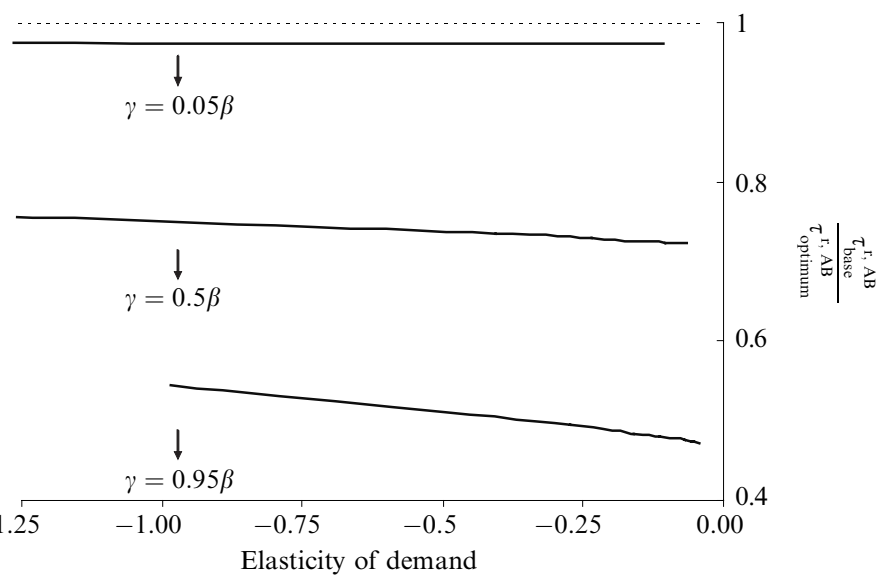

Figure 2. Fare ratio as a function of the demand elasticity.

the argument given in the previous section apparently holds for all likely values of the price elasticity of demand.

The fare ratio reflects the extent to which the public transport fare is adjusted in order to compensate for uninternalized congestion on the road. Figure 2 shows, for three 'relative levels' of cross-demand sensitivity $\gamma$ ( $\gamma$ remains a fixed proportion of $\beta$ when moving along the horizontal axis), how this ratio varies with equilibrium demand elasticity. There are two reasons why, for a given relative $\gamma$, this ratio falls when demand becomes less elastic (when moving to the right). First, less elastic demand in the rail market means that the deadweight loss from fare reductions, below marginal costs, become smaller, so a larger reduction in the rail fare becomes justifiable for the purpose of alleviating road congestion. Second, when demand becomes less elastic in the road market (also when moving to the right), a fare subsidy is less strongly frustrated by induced latent demand filing up the road capacity left unused by those who have switched to rail. This smaller frustration warrants a higher subsidy on the rail fare, and hence a lower fare ratio. Note that this mechanism parallels that found for the classic two-route problem (eg Verhoef et al, 1996).

The three curves show that the ratio between the rail fares in scenario I and scenario II in the AB market is lower when the cross-demand sensitivity (that is, the relative value of $\gamma$ ) is higher: a lower rail fare then leads to a stronger reduction in road congestion so a stronger deviation from marginal cost fares is warranted. When cross-demand sensitivity is relatively low, the welfare gain from a lower rail fare due to decreased congestion will be relatively low because only a few road users will switch to rail, and the fare is more strongly targeted to optimizing rail demand itself.

Next, we also expect that the distortion from private ownership will increase as demand becomes less elastic. Figure 3 plots the relative efficiency indicator $\omega$ for private operations of the railway system with and without road congestion pricing [recall that $\omega=\left(W^{r}-W^{\mathrm{I}}\right) /\left(W^{\mathrm{II}}-W^{\mathrm{I}}\right)$, where $W^{r}$ is the social surplus in regime $r$, and $W^{\mathrm{I}}$ and $W^{\mathrm{II}}$ that in regimes I and II, respectively]. As expected, the relative welfare loss from private rail operations increases when demand becomes less elastic. Market power then increases so that there is more opportunity to set the price (well) above marginal costs to obtain monopoly rents. ${ }^{(13)}$ 


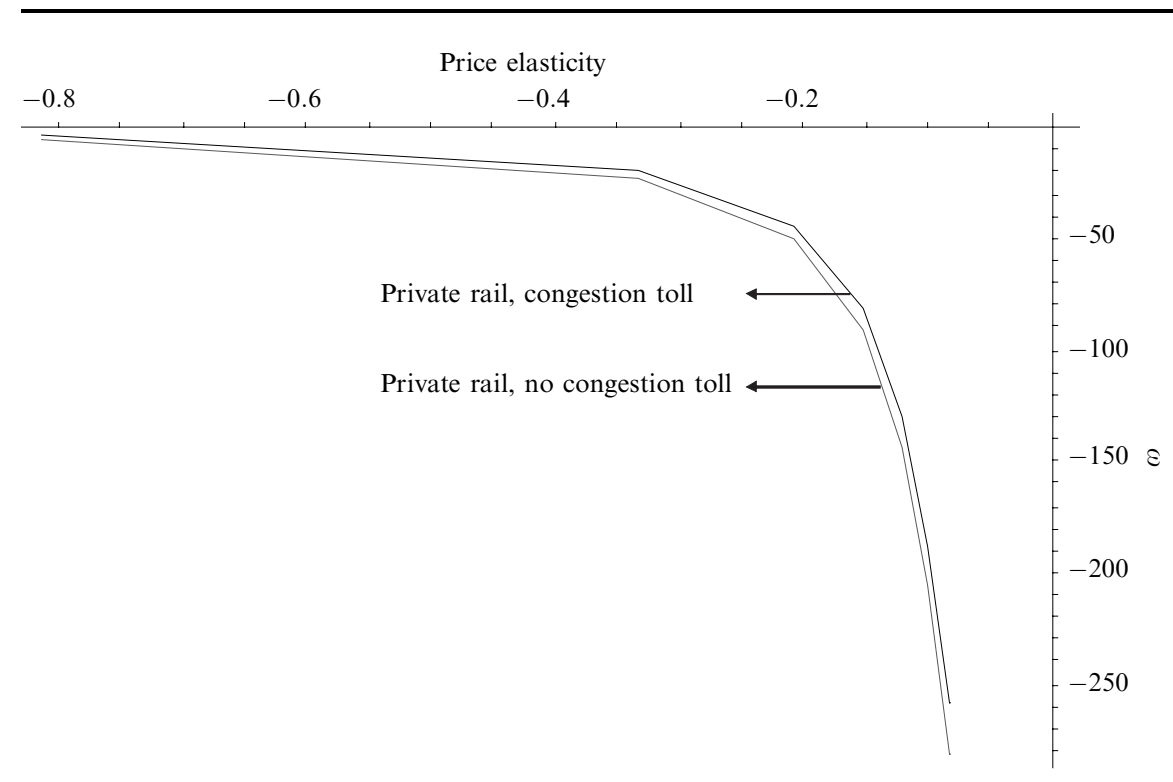

Figure 3. Welfare effects of private rail operations combined with a welfare-maximizing infrastructure charge.

The relative efficiency from private rail operations is lower without than with road congestion pricing. Road pricing provides the government with an extra instrument to counter the two main negative welfare effects from private rail operations, namely overpricing in the rail market itself, and excessive demand for road traffic. The vertical distance between the two curves in figure 3 increases when demand becomes more inelastic (this may be hard to see from the diagram, but was verified from the original model output), confirming the intuitive expectation that the relative importance of road pricing for these purposes increases when the distortions from private operations increase. The difference between the curves may not be as large as expected. The main reason is that, also without road pricing, the government still has road capacity available as a second-best instrument.

\section{Conclusion}

This paper explores competition between modes in urban transport networks and the implication for congestion tolls and infrastructure pricing. The results show how, for example, the rail fare charged by a public railway operator may increase when a congestion toll for the private car alternative is implemented, so that rail demand may decrease. The reason is that the second-best rail fare is relatively low, to compensate for excessive congestion on the road. The effect of the congestion toll on the rail fare depends directly on the level of substitution between the two alternatives: if the two alternatives are only very weak substitutes, the congestion toll will have only a limited effect on the second-best rail fare. This paper shows that, when the two modes can be considered to be substitutes, albeit imperfect substitutes, a congestion toll can have a significant impact on the rail fare. Such effects should be considered in the policy planning process.

A profit-maximizing private railway company sets the passenger output below the welfare optimum, and the fares are too high from a welfare-maximizing perspective. In this paper we argue that as a consequence, an infrastructure charge per train for a privatized railway company is negative when this charge is set to maximize welfare: the regulator uses the infrastructure charge partly to correct for the exploitation of market 
power by the private railway company. The infrastructure charge, however, is relatively small in absolute value in our model because it has only an indirect effect on the rail fare. The direct effect of the charge upon frequency would call for a zero charge, because the private operator chooses the socially optimal frequency given the belowoptimal aggregate demand. A charge or subsidy per passenger has a much stronger effect on the efficiency of private rail operations, as it directly influences the railway company's marginal cost.

Although extending the network beyond that of two competing links for the same market, the setup in the present paper is of course still rather simple. Future extensions would for example allow for serial competition between private and/or public operators, larger networks, and different frequencies and train capacities over the rail network. But also in terms of policy regimes, there is still much room for further research. One topic that we hope to address soon considers the analysis of the effects of different types of auctions for the right to perform private operations upon the efficiency of rail-road competition.

Acknowledgements. This research was made possible by research grant SP-U03/29 from the Volvo Research Foundation and financial support from NWO (project 014-34-540: railway stations and urban dynamics). The authors would like to thank two anonymous referees for their useful comments.

\section{References}

Arnott R, Yan A, 2000, "The two mode problem: second best pricing and capacity" Review of Urban and Regional Development Studies 12170 - 199

De Borger B, Proost S, van Dender K, 2005, "Congestion and tax competition in a parallel network" European Economic Review 492013 - 2040

De Palma A, Lindsey R, 2000, "Private roads: competition under various ownership regimes" Annals of Regional Science $3413-35$

Department for Transport, 2003, "National Transport Model, WP 3, http://www.dft.gov.uk/stellent/ groups/dft_econappr/documents/page/dft_econappr_024020.hcsp

Edelson N E, 1971, "Congestion tolls under monopoly" American Economic Review 61 872 - 882

Glaister S, Lewis D, 1978, "An integrated fares policy for transport in London” Journal of Public Economics 9341 - 355

Mills D E, 1981, "Ownership arrangements and congestion-prone facilities" American Economic Review, Papers and Proceedings $71493-502$

Oum T H, Water W G II, 2000, "Transport demand elasticities", in Handbook of Transport Modelling Eds D A Hensher, K J Button (Elsevier Science, Oxford) pp 197 -209

Parry I W H, Small K A, 2005, "On the optimal fares for public transport", paper presented at the "Success and failure of traffic demand measures" symposium, Napier University, Edinburgh, August, http://www.tri.napier/ac.uk/events/events.htm

Small K A, 1992 Urban Transportation Economics: Fundamentals of Pure and Applied Economics (Harwood, Chur)

Verhoef E T, Small K A, 2004, "Product differentiation on roads: constrained congestion pricing with heterogeneous users" Journal of Transport Economics and Policy 38127 - 150

Verhoef E T, Nijkamp P, Rietveld P, 1996, "Second-best congestion pricing: the case of an untolled alternative" Journal of Urban Economics $40279-302$ 


\section{Appendix A}

\section{The first-best solution for the general model}

For simplicity, and without loss of generality, we assume that $n^{j}=1$. The first-order necessary conditions are:

$$
\begin{aligned}
& \frac{\partial \Lambda}{\partial q_{\mathrm{r}}^{j}}=-\sum_{l=1}^{J} n^{l} \frac{\partial p_{\mathrm{r}}^{l}}{\partial q_{\mathrm{r}}^{j}} q_{\mathrm{r}}^{l}+n^{j} \tau_{\mathrm{r}}^{j}-\frac{\partial \mathrm{C}^{\mathrm{s}}(\cdot)}{\partial q_{\mathrm{r}}^{j}}-\frac{\partial \mathrm{C}_{\mathrm{r}}^{\mathrm{t}}(\cdot)}{\partial q_{\mathrm{r}}^{j}}+\sum_{l=1}^{J} \lambda_{\mathrm{r}}^{l}\left[\frac{\partial p_{\mathrm{r}}^{l}}{\partial q_{\mathrm{r}}^{j}}-\frac{\partial \mathrm{c}_{\mathrm{r}}^{l}(\cdot)}{\partial q_{\mathrm{r}}^{j}}\right]=0, \\
& \frac{\partial \Lambda}{\partial q_{\mathrm{p}}^{j}}=-\sum_{l=1}^{J} n^{l} \frac{\partial p_{\mathrm{p}}^{l}}{\partial q_{\mathrm{p}}^{j}} q_{\mathrm{p}}^{l}+\sum_{k=1}^{K} \delta_{\mathrm{p}}^{j, k} n^{j} \tau_{\mathrm{p}}^{k}-\frac{\partial \mathrm{C}_{\mathrm{p}}^{\mathrm{s}}(\cdot)}{\partial q_{\mathrm{p}}^{j}}+\sum_{l=1}^{J} \lambda_{\mathrm{p}}^{l}\left[\frac{\partial p_{\mathrm{p}}^{l}}{\partial q_{\mathrm{p}}^{j}}-\frac{\partial \mathrm{c}_{\mathrm{p}}^{l}(\cdot)}{\partial q_{\mathrm{p}}^{j}}\right]=0, \\
& \frac{\partial \Lambda}{\partial f_{\mathrm{r}}}=-\frac{\partial C_{\mathrm{r}}^{\mathrm{t}}(\cdot)}{\partial f_{\mathrm{r}}}-\sum_{j=1}^{J} \lambda_{\mathrm{r}}^{j} \frac{\partial \mathrm{c}_{\mathrm{r}}^{j}(\cdot)}{\partial f_{\mathrm{r}}}=0 \\
& \frac{\partial \Lambda}{\partial \tau_{\mathrm{r}}^{j}}=n^{j} q_{\mathrm{r}}^{j}-\lambda_{\mathrm{r}}^{j}=0, \\
& \frac{\partial \Lambda}{\partial \tau_{\mathrm{p}}^{k}}=\sum_{j=1}^{J} \sum_{k=1}^{K} \delta_{\mathrm{p}}^{j, k} n^{j} q_{\mathrm{p}}^{j}-\sum_{j=1}^{J} \sum_{k=1}^{K} \lambda_{\mathrm{p}}^{j} \delta_{\mathrm{p}}^{j, k}=0 \\
& \frac{\partial \Lambda}{\partial w_{\mathrm{r}}}=-\frac{\partial \mathbf{C}_{\mathrm{r}}^{\mathrm{s}}(\cdot)}{\partial w_{\mathrm{r}}}-\sum_{j=1}^{J} \lambda_{\mathrm{r}}^{j} \frac{\partial \mathrm{c}_{\mathrm{r}}^{j}(\cdot)}{\partial w_{\mathrm{r}}}=0 \\
& \frac{\partial \Lambda}{\partial w_{\mathrm{p}}^{k}}=-\frac{\partial \mathbf{C}_{\mathrm{p}}^{\mathrm{s}}(\cdot)}{\partial w_{\mathrm{p}}^{k}}-\sum_{j=1}^{J} \lambda_{\mathrm{p}}^{j} \frac{\partial \mathrm{c}_{\mathrm{p}}^{j}(\cdot)}{\partial w_{\mathrm{p}}^{k}}=0, \\
& \frac{\partial \Lambda}{\partial v_{\mathrm{r}}}=-\frac{\partial C_{\mathrm{r}}^{\mathrm{s}}(\cdot)}{\partial v_{\mathrm{r}}}-\frac{\partial C_{\mathrm{r}}^{\mathrm{t}}(\cdot)}{\partial v_{\mathrm{r}}}-\sum_{j=1}^{J} \lambda_{\mathrm{r}}^{j} \frac{\partial \mathrm{c}_{\mathrm{r}}^{j}(\cdot)}{\partial v_{\mathrm{r}}}=0, \\
& \frac{\partial \Lambda}{\partial \lambda_{i}^{j}}=p_{i}^{j}-\mathrm{c}_{i}^{j}(\cdot)-\tau_{i}^{j}=0 .
\end{aligned}
$$

We cannot solve for link-specific road tolls because the sum of link tolls may be uniquely defined, the separate components (that is the link tolls) are not. Rewriting equation (A5) for the case of a route-specific toll yields:

$$
\frac{\partial \Lambda}{\partial \tau_{\mathrm{p}}^{j}}=n^{j} q_{\mathrm{p}}^{j}-\lambda_{\mathrm{p}}^{j}=0
$$

Solving the first-order conditions yields the expected results that the optimal rail fare and congestion tolls are equal to the marginal social costs:

$$
\left.\begin{array}{rl}
\tau_{\mathrm{r}}^{j} & =\frac{1}{n^{j}}\left(\frac{\partial C^{\mathrm{s}}}{\partial q_{\mathrm{r}}^{j}}+\frac{\partial C_{\mathrm{r}}^{\mathrm{t}}}{\partial q_{\mathrm{r}}^{j}}\right)+\sum_{l=1}^{J} q_{\mathrm{r}}^{l} \frac{\partial c_{\mathrm{p}}^{l}}{\partial q_{\mathrm{r}}^{j}}, \\
\tau_{\mathrm{p}}^{j} & =\frac{1}{n^{j}}\left(\frac{\partial C_{\mathrm{p}}^{\mathrm{s}}}{\partial q_{\mathrm{p}}^{j}}\right)+\sum_{l=1}^{J} q_{\mathrm{p}}^{l} \frac{\partial c_{\mathrm{p}}^{l}}{\partial q_{\mathrm{p}}^{j}} .
\end{array}\right\}
$$

We can derive link-specific tolls in the numerical model because of the specific network structure used in the analysis. 


\section{Appendix B}

\section{Equality of infrastructure and congestion costs in the rail market}

Let the rail infrastructure cost be given by $C_{\mathrm{r}}^{\mathrm{s}}=\mu_{\mathrm{r}} w_{\mathrm{r}}$ : the infrastructure, connecting the three nodes, has fixed capacity $w_{\mathrm{r}}$ (which is constant over all links and markets). Then rewriting equation (A6) yields, while substituting $q_{\mathrm{r}}^{j}$ for $\lambda_{\mathrm{r}}^{j}$,

$$
\begin{gathered}
\frac{\partial \Lambda}{\partial w_{\mathrm{r}}}=-\frac{\partial C_{\mathrm{r}}^{\mathrm{s}}(\cdot)}{\partial w_{\mathrm{r}}}-\sum_{j=1}^{J} q_{\mathrm{r}}^{j} \frac{\partial c_{\mathrm{r}}^{j}(\cdot)}{\partial w_{\mathrm{r}}}=0 \\
\Leftrightarrow \mu_{\mathrm{r}}=q_{\mathrm{r}}^{\mathrm{AB}} \chi_{1}^{\mathrm{r}, \mathrm{AB}} \frac{f_{\mathrm{r}}}{w_{\mathrm{r}}^{2}}+q_{\mathrm{r}}^{\mathrm{BC}} \chi_{1}^{\mathrm{r}, \mathrm{BC}} \frac{f_{\mathrm{r}}}{w_{\mathrm{r}}^{2}}+q_{\mathrm{r}}^{\mathrm{AC}} \chi_{1}^{\mathrm{r}, \mathrm{AC}} \frac{f_{\mathrm{r}}}{w_{\mathrm{r}}^{2}} \\
\Leftrightarrow \mu_{\mathrm{r}} w_{\mathrm{r}}=q_{\mathrm{r}}^{\mathrm{AB}} \chi_{1}^{\mathrm{r}, \mathrm{AB}} \frac{f_{\mathrm{r}}}{w_{\mathrm{r}}}+q_{\mathrm{r}}^{\mathrm{BC}} \chi_{1}^{\mathrm{r}, \mathrm{BC}} \frac{f_{\mathrm{r}}}{w_{\mathrm{r}}}+q_{\mathrm{r}}^{\mathrm{AC}} \chi_{1}^{\mathrm{r}, \mathrm{AC}} \frac{f_{\mathrm{r}}}{w_{\mathrm{r}}} .
\end{gathered}
$$

Thus, the rail infrastructure costs are equal to the total rail congestion costs as defined in equation (22).

Rewriting equation (A7) yields

$$
-\sum_{j=1}^{J} q_{\mathrm{p}}^{j} \frac{\partial \mathrm{c}_{\mathrm{p}}^{j}(\cdot)}{\partial w_{\mathrm{p}}^{k}}=\frac{\partial \mathrm{C}_{\mathrm{p}}^{\mathrm{s}}(\cdot)}{\partial w_{\mathrm{p}}^{k}} \Leftrightarrow q_{\mathrm{r}}^{\mathrm{AB}} \chi_{1}^{\mathrm{p}} \frac{q_{\mathrm{r}}^{\mathrm{AB}}+q_{\mathrm{r}}^{\mathrm{AC}}}{\left(w_{\mathrm{p}}^{\mathrm{AB}}\right)^{2}}+q_{\mathrm{r}}^{\mathrm{AC}} \chi_{1}^{\mathrm{p}} \frac{q_{\mathrm{r}}^{\mathrm{AB}}+q_{\mathrm{r}}^{\mathrm{AC}}}{\left(w_{\mathrm{p}}^{\mathrm{AB}}\right)^{2}}=\mu_{\mathrm{p}}^{\mathrm{AB}},
$$

and

$$
-\sum_{j=1}^{J} q_{\mathrm{p}}^{j} \frac{\partial c_{\mathrm{p}}^{j}(\cdot)}{\partial w_{\mathrm{p}}^{k}}=\frac{\partial C_{\mathrm{p}}^{\mathrm{s}}(\cdot)}{\partial w_{\mathrm{p}}^{k}} \Leftrightarrow q_{\mathrm{r}}^{\mathrm{BC}} \chi_{1}^{\mathrm{p}} \frac{q_{\mathrm{r}}^{\mathrm{BC}}+q_{\mathrm{r}}^{\mathrm{AC}}}{\left(w_{\mathrm{p}}^{\mathrm{BC}}\right)^{2}}+q_{\mathrm{r}}^{\mathrm{AC}} \chi_{1}^{\mathrm{p}} \frac{q_{\mathrm{r}}^{\mathrm{BC}}+q_{\mathrm{r}}^{\mathrm{AC}}}{\left(w_{\mathrm{p}}^{\mathrm{BC}}\right)^{2}}=\mu_{\mathrm{p}}^{\mathrm{BC}} .
$$

Rewriting equation (A2) yields [in the optimum ${ }^{(14)}$ ]:

$$
\begin{aligned}
\sum_{k=1}^{K} \delta_{\mathrm{p}}^{j, k} \tau_{\mathrm{p}}^{k}=\sum_{l=1}^{J} q_{\mathrm{p}}^{l} \frac{\partial c_{\mathrm{p}}^{l}(\cdot)}{\partial q_{\mathrm{p}}^{j}} & \\
& \stackrel{j=\mathrm{AB}}{\Leftrightarrow} \tau_{\mathrm{p}}^{\mathrm{AB}}=\chi_{1}^{\mathrm{p}}\left(\frac{q_{\mathrm{p}}^{\mathrm{AB}}}{w_{\mathrm{p}}^{\mathrm{AB}}}+\frac{q_{\mathrm{p}}^{\mathrm{AC}}}{w_{\mathrm{p}}^{\mathrm{AB}}}\right) \\
& j=\mathrm{BC} \tau_{\mathrm{p}}^{\mathrm{BC}}=\chi_{1}^{\mathrm{p}}\left(\frac{q_{\mathrm{p}}^{\mathrm{BC}}}{w_{\mathrm{p}}^{\mathrm{BC}}}+\frac{q_{\mathrm{p}}^{\mathrm{AC}}}{w_{\mathrm{p}}^{\mathrm{BC}}}\right) \\
& \quad j=\mathrm{AC} \\
& \Leftrightarrow \tau_{\mathrm{p}}^{\mathrm{AB}}+\tau_{\mathrm{p}}^{\mathrm{BC}}=\chi_{1}^{\mathrm{p}}\left(\frac{q_{\mathrm{p}}^{\mathrm{AB}}}{w_{\mathrm{p}}^{\mathrm{AB}}}+\frac{q_{\mathrm{p}}^{\mathrm{BC}}}{w_{\mathrm{p}}^{\mathrm{BC}}}+\frac{q_{\mathrm{p}}^{\mathrm{AC}}}{w_{\mathrm{p}}^{\mathrm{AB}}}+\frac{q_{\mathrm{p}}^{\mathrm{AC}}}{w_{\mathrm{p}}^{\mathrm{BC}}}\right) .
\end{aligned}
$$

From equations (B2), (B3), and (B4) it follows that in equilibrium,

$$
\tau_{\mathrm{p}}^{\mathrm{AB}} q_{\mathrm{p}}^{\mathrm{AB}}+\tau_{\mathrm{p}}^{\mathrm{BC}} q_{\mathrm{p}}^{\mathrm{BC}}+\left(\tau_{\mathrm{p}}^{\mathrm{AB}}+\tau_{\mathrm{p}}^{\mathrm{BC}}\right) q_{\mathrm{p}}^{\mathrm{AC}}=w_{\mathrm{p}}^{\mathrm{AB}} \mu_{\mathrm{p}}^{\mathrm{AB}}+w_{\mathrm{p}}^{\mathrm{BC}} \mu_{\mathrm{p}}^{\mathrm{BC}},
$$

so that the toll revenues are sufficient to finance capacity.

(14) Note that in the optimum $\lambda_{\mathrm{r}}^{j}=q_{\mathrm{r}}^{j}$, so that equations (B2)-(B4) hold in the optimum. 
Conditions of use. This article may be downloaded from the E\&P website for personal research by members of subscribing organisations. This PDF may not be placed on any website (or other online distribution system) without permission of the publisher. 